\title{
A PRODUÇÃO DO TEXTO ARGUMENTATIVO: ANÁLISE A PARTIR DE UMA EXPERIÊNCIA DE EXTENSÃO EM UMA TURMA DE EJA
}

\author{
José Marcelino Ferreira Júnior; Ilane Ferreira Cavalcante \\ marcellinjr@gmail.com; ilanecfc@gmail.com \\ Universidade Federal do Rio Grande do Norte; Instituto Federal de Educação, Ciência e \\ Tecnologia do Rio Grande do Norte \\ DOI: $10.15628 /$ rbept.2018.6888
}

Artigo submetido em dez/2017 e aceito em mar/2018

\section{RESUMO}

Este artigo apresenta reflexões sobre uma experiência do Projeto de Colaboração Pedagógica entre IFRN e Escolas Públicas Estaduais do RN desenvolvida pelo Grupo de Pesquisa em Multirreferencialidade, Educação e Linguagem (GPMEL) sob a perspectiva do trabalho colaborativo (DAMIANI, 2008). O IFRN, em seu Projeto Político Pedagógico (PPP), apresenta perspectivas de formação de professores indicando a necessidade de que os estudantes em formação conheçam a realidade das regiões onde estão inseridos. Projetos de extensão como o apresentado aqui permite essa inserção dos estudantes na realidade da educação pública e os prepara, no caso específico, para lidar com as necessidades dos estudantes da modalidade EJA. A experiência em foco traz os resultados de uma oficina de Língua Portuguesa focada no desenvolvimento do texto argumentativo. Analisa-se, a experiência e os textos à luz de autores como Cerqueira (2007), Lucena (2004) e Arroyo (2005). A análise da redação produzida pelos estudantes no âmbito da oficina é avaliada a partir da tentativa de compreender a heterogeneidade do grupo de EJA e suas dificuldades mais recorrentes e visando não só contribuir para a prática da escrita, mas para a formação dos estudantes envolvidos e para a organização de futuros trabalhos de extensão.

Palavras-chave: Trabalho colaborativo, Extensão, Educação de Jovens e Adultos, Ensino de Língua Portuguesa. 


\title{
THE PRODUCTION OF ARGUMENTATIVE TEXTS IN YOUNG AND ADULTS CLASSROOMS: ANALYSING TEXTS DEVELOPED DURING AN EXTENSION WORKSHOP
}

\begin{abstract}
This paper presents some reflections about an extension activity developed as part of the project Pedagogical collaborative work between IFRN and Public Schools from RN leaded by the Group of Research in Multireference studies, Education and Language (GPMEL) under the perspective of collaborative work (DAMIANI, 2008). The Pedagogical and Political Project (PPP) from IFRN presents the need to form teachers that know the reality of where they will perform professionally. Extension projects as the one presented here may help students to deal with the reality of the public schools and also with the needs of EJA students. This article will bring the results of a workshop of Portuguese focused on the production of argumentative texts. The analysis is based on the authors such as Cerqueira (2007), Lucena (2004) and Arroyo (2005). The texts written by the students at the workshop support not only the analysis of the diversity in EJA classes, but also helps to understand their most common difficulties, contributing to the licentiate degree students in their formation and preparing GPMEL's components to future extension projects.
\end{abstract}

Keywords: Collaborative work, Extension, Youth and Adults Education, Portuguese Language Teaching.

\section{PRIMEIRAS PALAVRAS: EXTENSÃO, PESQUISA E FORMAÇÃO DE PROFESSORES}

\footnotetext{
É exatamente em suas relações dialéticas com a realidade que iremos discutir a educação como um processo de constante libertação do homem. Educação que, por isto mesmo, não aceitará nem o homem isolado do mundo - criando este em sua consciência -, nem tampouco o mundo sem o homem - incapaz de transformá-lo.
}

Em consonância com Freire (2002), cuja epígrafe abre este trabalho, a extensão é percebida como diálogo, relação do homem com seu contexto. Enquanto processo educacional, a extensão objetiva fortalecer a relação entre a instituição de ensino e a sociedade como forma de contribuir para o desenvolvimento educativo, cultural, artístico, científico e tecnológico da comunidade. 
Dessa forma, a ação extensionista articula o ensino e a pesquisa na busca pela democratização do conhecimento com a participação efetiva da comunidade junto à instituição de ensino superior (IES), que pode, por sua vez produzir conhecimento resultante do confronto com essa realidade.

O Plano Nacional de Extensão Universitária considera, em conformidade com o I Encontro Nacional de Pró-Reitores de Extensão, que

\begin{abstract}
A Extensão é uma via de mão-dupla, com trânsito assegurado à comunidade acadêmica, que encontrará, na sociedade, a oportunidade de elaboração da práxis de um conhecimento acadêmico. No retorno à Universidade, docentes e discentes trarão um aprendizado que, submetido à reflexão teórica, será acrescido àquele conhecimento. Esse fluxo, que estabelece a troca de saberes sistematizados, acadêmico e popular, terá como consequência: a produção do conhecimento resultante do confronto com a realidade brasileira e regional; a democratização do conhecimento acadêmico e a participação efetiva da comunidade na atuação da Universidade. (BRASIL, 2012, p. 8).
\end{abstract}

As ações de extensão também promovem a formação da cidadania, pois a inserção dos profissionais da instituição nas comunidades permite que estes se situem historicamente e se identifiquem culturalmente e, assim, podem referenciar sua atuação profissional com os problemas que afligem a sociedade agindo na busca de uma sociedade justa e igualitária. Em consequência,

As atividades de Extensão Universitária constituem aportes decisivos à formação do estudante, seja pela ampliação do universo de referência que ensejam, seja pelo contato direto com as grandes questões contemporâneas que possibilitam. Esses resultados permitem o enriquecimento da experiência discente em termos teóricos e metodológicos, ao mesmo tempo em que abrem espaços para reafirmação e materialização dos compromissos éticos e solidários da Universidade Pública brasileira. (BRASIL, 2006, p. 20).

A lei de criação dos Institutos Federais, Lei 11. 892/2008, determina, entre os objetivos dos institutos federais, o de "desenvolver atividades de extensão de acordo com os princípios e finalidades da educação profissional e tecnológica, em articulação com o mundo do trabalho e os segmentos sociais". Para alcançar esse objetivo legal, e conforme seu Projeto Político Pedagógico (PPP), o Instituto Federal de Educação, Ciência e Tecnologia do Rio Grande do Norte 
(IFRN) vem estimulando, por meio de editais, o desenvolvimento de ações de extensão que incluam a comunidade interna e externa:

[...] a extensão estabelece-se por meio de práticas planejadas, envolvendo não só parceria com organizações governamentais e não governamentais, instituições nacionais e internacionais, empresas, indústrias e pessoas como também prestação de serviços. (IFRN, 2012, p. 188).

A Resolução n 35/2006-CD, que aprova as normas para as atividades de extensão no âmbito do IFRN, apresenta, entre as ações extensionistas, o que considera modalidade de curso, assim definida, "Conjunto articulado de ações pedagógicas, de caráter teórico ou prático, presencial ou a distância, planejadas e organizadas de modo sistemático".

OPPP do IFRN acrescenta, entre as perspectivas de extensão presentes no instituto, o estímulo para que os educadores conheçam "[...] a realidade das regiões onde os campi estão inseridos, identificando problemas e potencialidades. Elaborando projetos que possam ser desenvolvidos "[...] com a participação dos servidores (docentes e técnico-administrativos), estudantes e a comunidade externa, os projetos de extensão, implementados na perspectiva de atuação conjunta com o ensino e a pesquisa, resultam em efetiva intervenção na realidade." (IFRN, 2012, p. 189).

A concepção de extensão presente no PPP do IFRN parte da indicação de três níveis de extensão: a assistencialista, a moderna e a emancipatória, informando que as três são úteis dentro de determinados contextos, mas que a primeira, a assistencialista, não leva à cidadania plena e, portanto, o IFRN considera que é preciso

[...] perseguir e planejar um conjunto de atividades que resultem na confluência dos três perfis de extensão: o assistencialista, o moderno e o emancipatório. Deve-se enfatizar, em especial, o viés da construção e do fortalecimento da cidadania, sob as bases da autonomia, do protagonismo identitário, da participação social e do respeito à diversidade e à diferença, entre outras plataformas que respaldam práticas favorecedoras da emancipação dos sujeitos. (IFRN, 2012, p. 190).

No que tange à formação docente, estabelecida para os Institutos Federais pela lei 11.892/2008, que destina $20 \%$ das vagas para as licenciaturas, o IFRN se apresenta como espaço de formação profissional e como espaço de formação de professores. Os institutos federais podem articular uma formação docente dentro de suas perspectivas de formação profissional, mas nem sempre as articula pensando as diferentes modalidades educacionais. 
Ensinar é uma pratica complexa em todas as suas nuances, quando o professor atua na Educação de Jovens e Adultos precisa de uma preparação para isso. Essa modalidade de ensino se propõe a atender um público ao qual foi negado o direito à educação durante a infância e/ou adolescência, seja pela oferta irregular de vagas, seja pelas inadequações do sistema de ensino ou pelas condições socioeconômicas desfavoráveis dos estudantes.

Para que o professor possa atuar, oferecendo aos jovens e adultos uma educação integral que concilie a formação técnica com a humana, de qualidade, é preciso que ele atue também como pesquisador, conhecendo a realidade onde poderá atuar, construindo os instrumentos didáticos adequados às diversas turmas e espaços. Assim, ele poderá possibilitar aos estudantes a formação de cidadãos capazes de interagir com o meio e criar alternativas de inserção e permanência no mundo do trabalho com criticidade. Esse processo de pesquisa do professor exige tempo para ler, refletir e construir materiais didáticos.

Pensando nessas questões e procurando articular ensino, pesquisa e extensão na formação de estudantes de ensino superior e pós-graduação, o Grupo de Pesquisa em Multirreferencialidade, Educação e Linguagem (GPMEL) do IFRN tem desenvolvido, desde 2013, projetos de extensão que buscam construir ações colaborativas com escolas públicas municipais e estaduais do Rio Grande do Norte. Essas ações ocorrem, em geral, por meio de oficinas ou minicursos desenvolvidos a partir das demandas identificadas em cada escola parceira e tem como público alvo professores ou estudantes do ensino fundamental ou médio em qualquer de suas modalidades.

Este artigo se debruça sobre as experiências desenvolvidas no projeto de extensão Colaboração Pedagógica entre o Campus EaD/IFRN e escolas públicas do RN. Esse projeto se desenvolveu em duas escolas públicas de Natal e Parnamirim, Centro de Educação de Jovens e Adultos Lagoa Nova (CEJA Lagoa Nova) e Escola Estadual Presidente Roosevelt, respectivamente.

$\mathrm{Na}$ escola situada em Parnamirim apenas uma oficina, a de Educação Ambiental, pôde ser desenvolvida, devido ao calendário escolar e à falta de espaço adequado para o desenvolvimento das demais oficinas. Na segunda, foram desenvolvidas 5 oficinas: Geografia, Língua portuguesa, Língua espanhola, Matemática e Novas Tecnologias.

Este artigo trata, especificamente, sobre a oficina de Língua Portuguesa, desenvolvida em uma turma de EJA, focada na construção do texto argumentativo e analisando, a partir da produção textual dos estudantes, suas principais dificuldades de escrita. Para refletir sobre esse processo, traça-se uma pequena reflexão sobre a extensão como elemento articulador do ensino e da pesquisa na formação docente, sobre os objetivos e as políticas de EJA no Brasil e, por fim, sobre a experiência desenvolvida na escola em foco e as produções textuais resultantes.

\section{EDUCAÇÃO DE JOVENS E ADULTOS: UMA BREVE REFLEXÃO}

A Lei de Diretrizes e Bases da Educação Nacional (LDB), de 1996, dedicou à Educação de Jovens e Adultos toda uma seção. As orientações gerais quanto à EJA estão apresentadas em dois 
artigos, especificamente, Art. 37 e 38, que asseguram a gratuidade, por conta da especificidade desta população e os vínculos de sua educação com o mundo do trabalho. 0 Art. 37estabelece que

$\S 1^{\circ}$ Os sistemas de ensino assegurarão gratuitamente aos jovens e aos adultos, que não puderam efetuar os estudos na idade regular, oportunidades educacionais apropriadas, consideradas as características do alunado, seus interesses, condições de vida e de trabalho, mediante cursos e exames.

$\S 2^{\circ} 0$ Poder Público viabilizará e estimulará o acesso e a permanência do trabalhador na escola, mediante ações integradas e complementares entre si.

$\S 3$ A educação de jovens e adultos deverá articular-se, preferencialmente, com a educação profissional, na forma do regulamento (BRASIL, 1996, p.1)

As Diretrizes Curriculares Nacionais de 2000 definiram os objetivos da EJA: restaurar o direito à educação, negado aos jovens e adultos; oferecer a eles igualdade de oportunidades para a entrada e permanência no mercado de trabalho e qualificação para uma educação permanente.

A carência escolar de adultos e jovens que ultrapassaram essa idade tem graus variáveis, desde a total falta de alfabetização, passando pelo analfabetismo funcional, até a incompleta escolarização nas etapas do Ensino Fundamental e do Médio. Essa defasagem educacional mantém e reforça a exclusão social, privando largas parcelas da população ao direito de participar dos bens culturais, de integrar-se na vida produtiva e de exercer sua cidadania. Esse resgate não pode ser tratado emergencialmente, mas, sim, de forma sistemática e continuada, uma vez que jovens e adultos continuam alimentando o contingente com defasagem escolar, seja por não ingressarem na escola, seja por dela se evadirem por múltiplas razões. (BRASIL, 2013, p.40)

As metas 09 e 10 do Plano Nacional de Educação (PNE) indicam a necessidade de formação do público Jovem e Adulto no Brasil:

Meta 09: Alfabetização e alfabetismo funcional de jovens e adultos. Elevar a taxa de alfabetização da população com 15 (quinze) anos ou mais para 93,5\% (noventa e três inteiros e cinco décimos por cento) até 2015 e, até o final da vigência deste PNE, erradicar 
o analfabetismo absoluto e reduzir em $50 \%$ (cinquenta por cento) a taxa de analfabetismo funcional.

Meta 10: EJA integrada à Educação Profissional. Oferecer, no mínimo, 25\% (vinte e cinco por cento) das matrículas de educação de jovens e adultos, nos ensinos fundamental e médio, na forma integrada à educação profissional. (BRASIL, 2014).

Ao atrair o adulto para a escola, no entanto, é preciso garantir que ele não a abandone. As taxas de evasão têm origem em vários fatores, que dizem respeito a aspectos extrínsecos e intrínsecos à escola. Entre os aspectos intrínsecos, o uso de material didático e metodologias inadequadas para a faixa etária, conteúdos sem significado e horários de aula que não respeitam a rotina de quem estuda e trabalha são alguns dos problemas. Desses, os que estão ao alcance do professor exigem que ele conheça as especificidades desse público e use a realidade do aluno como eixo condutor das aprendizagens. Para isso, o professor precisa ter contato com essa realidade ainda em seu processo de formação.

O estar de cada um no mundo é repleto de ações que levam a aprender. A aprendizagem, por sua vez, acontece num entrelaçamento entre informação, conhecimento e saber. As informações que recebidas do outro, nos espaços externos, acionam estruturas mentais movimentando o organismo, o corpo, as esferas dramáticas e cognitivas, transformando-se em conhecimento que se incorpora em saberes individuais (CERQUEIRA, 2007). Dessa maneira, o saber se constitui a partir das experiências e vivências do cotidiano, e as aprendizagens primeiras acontecem por meio das relações familiares; somente mais tarde, ao ingressar na escola, ampliando as relações sociais, esses diferentes saberes podem ser transformados em saberes científicos, técnicos ou acadêmicos.

Os alunos e alunas de EJA trazem consigo uma visão de mundo influenciada por seus traços culturais de origem e por sua vivência social, familiar e profissional. Pode-se dizer que eles trazem uma noção de mundo mais relacionada à prática do cotidiano, ao ver e ao fazer. Ao escolher o caminho da escola, eles são levados a operar uma ruptura nessa sua vivência e a refletir sobre suas práticas. Uma prática adequada dentro do espaço escolar proporciona a esses alunos e alunas a possibilidade de ficarem abertos à aprendizagem, receptivos, sensíveis, e também ativos: capazes de explorar, investigar, pensar e interferir no que olham.

A escola não pode fingir que essa modalidade de ensino comporta as mesmas práticas, currículos rígidos e metodologias típicas do modelo de ensino regular. Não é inclusão oferecer uma educação a esses indivíduos nos mesmos moldes do ensino regular, pois eles apresentam uma situação de vida extremamente diversa. A escola, para caracterizar-se como inclusiva, deve, antes de tudo, conhecer o estudante da EJA na sua especificidade.

O público da EJA, em sua quase totalidade, vivencia uma realidade social de marginalidade em que os direitos básicos lhes são negados e a luta pela sobrevivência coloca-se como a mais 
urgente. Os estudantes da EJA carregam consigo uma história escolar permeada por desistências, fracassos e insucessos. Diante dessa realidade, esses alunos chegam à escola com a autoestima abalada, desacreditados de que a construção de outra realidade é possível. Aliado a tudo isso, ainda, têm que conviver com um contexto socioeconômico extremamente perverso. Arroyo (2005, p.22-23) destaca que quanto

mais se avança na configuração da juventude e da vida adulta teremos mais elementos para configurar a especificidade da EJA, a começar por superar visões restritivas que tão negativamente a marcaram. Por décadas, o olhar escolar os enxergou apenas em suas trajetórias escolares truncadas: alunos enviados, reprovados, defasados, alunos com problemas de frequência, de aprendizagem, não concluintes da $1^{\circ}$ a $4^{\circ}$ ou da $5^{\circ}$ a $8^{\circ}$. Com esse olhar escolar sobre esses jovens - adultos, não avançaremos na configuração.

Esse olhar negativo da escola sobre o estudante da EJA tem contribuído para o fracasso do estudante. Oliveira (2001, p 18), ao elaborar um perfil geral do aluno da modalidade EJA, afirma que esse estudante

Traz consigo uma história mais longa (e provavelmente mais complexa) de experiências, conhecimentos acumulados e reflexões sobre o mundo externo, sobre si mesmo e sobre as outras pessoas. Com relação à inserção em situações de aprendizagem, essas peculiaridades da etapa da vida em que se encontra $o$ adulto fazem com que ele traga consigo diferentes habilidades e dificuldades (...) e, provavelmente, maior capacidade de reflexão sobre o conhecimento e sobre seus próprios processos de aprendizagem.

Pensar a própria identidade é uma das formas de fazer o aluno assumir a responsabilidade sobre sua própria formação e, dessa forma, envolver-se mais ativamente no processo de ensinoaprendizagem. A exploração das diferentes linguagens humanas, a utilização de materiais oriundos dos diferentes veículos a que esses indivíduos têm acesso em seu dia a dia; a reflexão sobre pautas atuais do contexto em que eles vivem, por exemplo, podem trazer mais significado para a sua aprendizagem. Pensando nesses aspectos, e imbuído do compromisso de formação docente a partir dos projetos de extensão de que faz parte, é que este artigo busca analisar a 
produção textual de alunos que participaram da oficina do projeto de extensão desenvolvido no CEJA Lagoa Nova em Natal/RN.

\section{UMA EXPERIÊNCIA EM CURSO: EXTENSÃO COLABORATIVA NA ÁREA DE LÍNGUA PORTUGUESA}

O projeto Colaboração Pedagógica entre o Campus EaD/IFRN e escolas públicas do RN foi a terceira versão de um projeto que tem sido desenvolvido pelo Grupo de Pesquisa em Multirreferencialidade, Educação e Linguagem desde 2013. O projeto tem uma perspectiva de trabalho colaborativo com as escolas parceiras.

O desenvolvimento de um projeto colaborativo tem que ser pensado a partir da interação de sujeitos visando um objetivo comum. Nesse caso, a realização de ações pedagógicas que contribuam para a melhoria da educação básica do Estado. 0 trabalho colaborativo contribui significativamente para que grupos trabalhem em conjunto, para que ações sejam negociadas e estabeleçam-se relações de diálogo e de compartilhamento (DAMIANI, 2008). 0 trabalho colaborativo permite aprendizagens mais ricas e a consolidação de valores de solidariedade e de respeito.

Outro pilar fundamental do projeto se estabelece a partir da junção entre teoria e prática. 0 verdadeiro valor da teoria consiste em sua "capacidade de estabelecer possibilidades de pensamento reflexivo por parte daqueles que a utilizam [...]", (GIROUX, 1986, p. 38).

Nessa perspectiva, a metodologia adotada organiza-se por meio de temas de interesse da escola envolvida no projeto. Cada um dos temas é trabalhado, coletivamente, por professores e alunos do IFRN (alunos de licenciatura e de pós-graduação) em oficinas pedagógicas compreendidas como estratégias didáticas que possibilitam a construção de conhecimentos teóricos e metodológicos relativos ao saber e ao fazer, a partir de leitura e produção de textos, das novas tecnologias da comunicação e informação e de língua espanhola.

O Centro de Educação de Jovens e Adultos (CEJA) Prof. Reginaldo Teófilo, funcionava em dois turnos (vespertino e noturno) com a modalidade da EJA compreendendo os períodos do $1^{\circ}$ ao $5^{\circ}$ ano do Ensino Fundamental, que eram concluídos em dois anos e meio, e o Ensino Médio, do $1^{\circ}$ ao $3^{\circ}$ período, cuja conclusão era possível em um ano e meio.

Conforme o Projeto pedagógico da escola (PP, 2008-2009) o público-alvo apresentava baixo poder aquisitivo e pouca escolarização. Além disso, a grande maioria era de trabalhadores, dificultando sua permanência cotidiana em sala de aula, o que também acabava por gerar desmotivação nos estudos.

Previamente, foi feito um contato com a Coordenação pedagógica da escola para identificar o seu interesse em receber o projeto. Confirmado o interesse, buscou-se identificar os conteúdos mais necessários, demandados pelos professores, para cada oficina e definir um calendário para cada uma das oficinas. 
A oficina de Língua Portuguesa foi programada para ser desenvolvida em 8 horas aulas e, no mínimo, dois encontros. 0 conteúdo da demanda foi a sequência textual argumentativa, pelo interesse dos estudantes em estudar para concursos e para o Exame Nacional do Ensino Médio (ENEM). No primeiro encontro os estudantes receberam um material didático desenvolvido pelo IFRN para os estudantes do $9^{\circ}$ ano do Ensino Fundamental que pretendiam fazer o exame de seleção para a entrada no Ensino Médio Integrado da instituição: dois livros e um DVD com vídeo aulas. 0 objetivo era ter o material como suporte para o estudo do conteúdo da oficina, prioritariamente.

A partir do material didático entregue, foram elaborados slides a serem apresentados pela equipe responsável pela oficina, no caso, uma professora do IFRN e um estudante de pósgraduação lato sensu da mesma instituição, ambos componentes do grupo de pesquisa. Também foi elaborada uma atividade de produção textual com a perspectiva de que, em um primeiro momento, os estudantes elaborassem o seu texto. Depois, que o professor fizesse uma avaliação do texto produzido e retornasse à sala de aula para que, em um segundo momento, os estudantes pudessem reescrever o seu texto com base na avaliação docente. Esse exercício de refletir sobre as falhas identificadas na produção textual permitiria um aprendizado prático e um desenvolvimento da escrita a partir da reflexão.

Infelizmente, apenas os momentos de produção e de avaliação foram concretizados, porque a escola entrou em um calendário de eventos inesperados que culminou com o seu fechamento ao final do ano de 2015 sem que a equipe do projeto pudesse ter a oportunidade de finalizar o seu trabalho. No entanto, no momento de culminância do projeto, um evento que procura reunir todos os partícipes, os estudantes de EJA foram convidados a fazer uma pequena fala sobre a sua experiência nas oficinas desenvolvidas e se mostraram não só frustrados pelo fechamento de seu espaço de aprendizagem, mas pela falta de continuidade de algumas das oficinas, entre elas, a de Língua Portuguesa, destacando a importância e a necessidade desse tipo de projeto em sua formação.

A produção textual proposta foi estimulada por meio de textos retirados de veículos de comunicação e elaborada conforme as regras e a formatação de enunciados de processos seletivos públicos, como o ENEM. Assim, primeiro se fez uma breve exposição dialogada sobre texto, sequencias textuais e o texto argumentativo. Depois, a leitura de um texto e uma análise da compreensão do texto pelos estudantes. Antes da aplicação da folha de produção textual. Nesse momento de leitura, houve estudantes que demonstraram forte dificuldade de compreensão leitora e houve um estudante que se recusou a participar da oficina (depois a equipe descobriu, por meio da coordenação pedagógica da escola, que ele não sabia ler).

A seguir, seguindo um formato de processo seletivo, foi entregue uma folha com os textos motivadores previamente lidos e a proposta de redação, um texto dissertativo-argumentativo. O tema definido para a produção textual foi a Redução da Maioridade Penal, um tema bastante discutido e recorrente na grande imprensa no momento da realização da oficina. A Figura 1 apresenta a folha de proposta de produção textual entregue aos estudantes. 


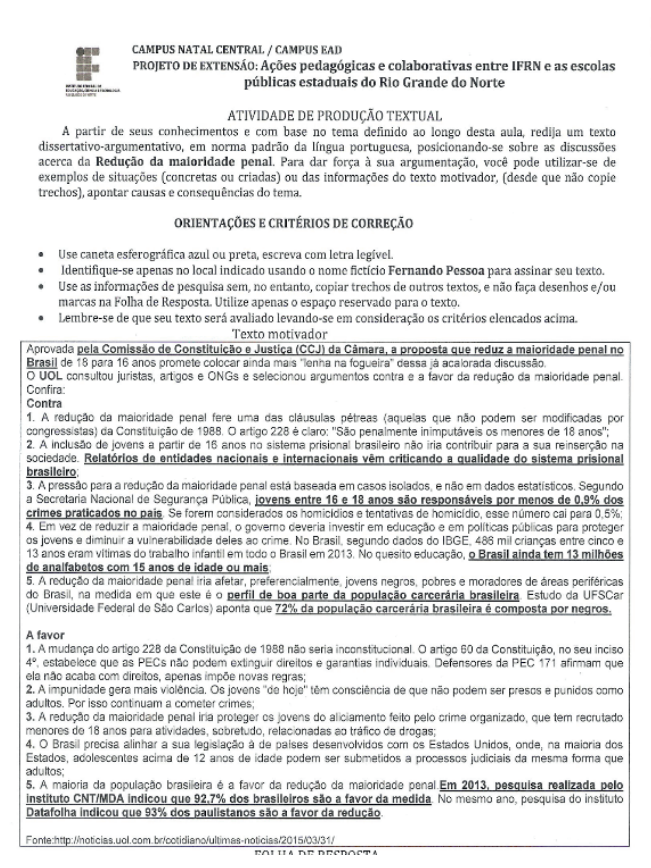

Figura 1: Folha de orientação para produção textual.

Fonte: Arquivo pessoal. Elaboração dos autores para a oficina em foco.

Os textos produzidos variaram muito em termos de qualidade linguística, desde textos mais precários em termos de aspectos básicos da linguagem a textos mais elaborados linguisticamente. O texto apresentado na Figura 2, por exemplo, é o que apresenta maiores problemas de textualidade, tais como ortografia, pontuação e organização lógica das ideias. Uma simples oficina não poderia contribuir de forma mais significativa para a solução de problemas de escrita do estudante que produziu o texto da Figura 2, mas permite que ele tenha um olhar individualizado sobre sua produção textual e reflita sobre as suas necessidades de aprendizagem.

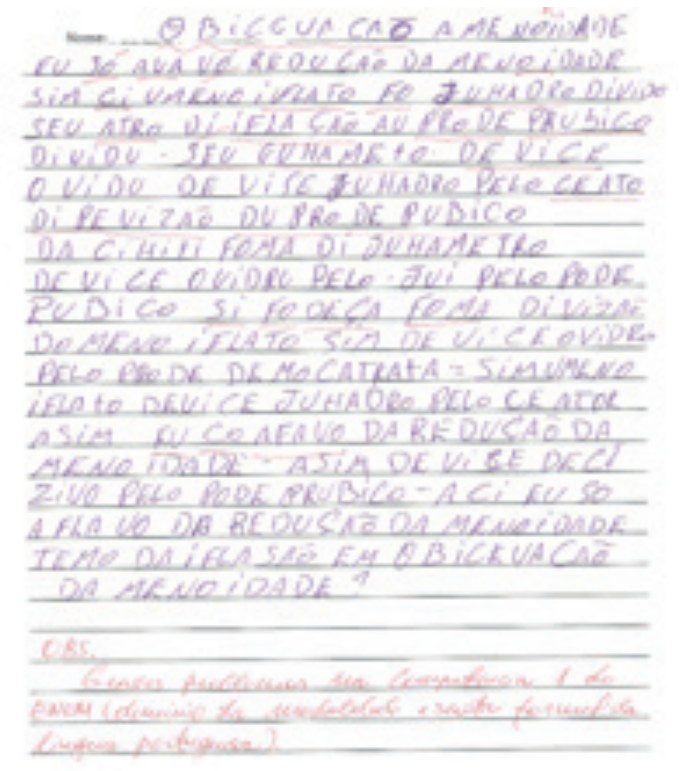

Figura 2: Texto com problemas significativos de textualidade

Fonte: Arquivo pessoal dos autores. Texto elaborado por estudante da oficina em foco. 
O texto apresentado na Figura 3, por outro lado, apresenta uma sequência de ideias lógicas, posicionamento do autor, indica compreensão de aspectos relevantes acerca do tema proposto, com apenas pequenos equívocos ortográficos, de pontuação e de uso inadequado de conectivos. Um texto que, com certeza, após uma reflexão do autor baseado na avaliação do professor, poderia proporcionar uma reescrita e um crescimento do estudante no que tange à produção de um texto argumentativo.

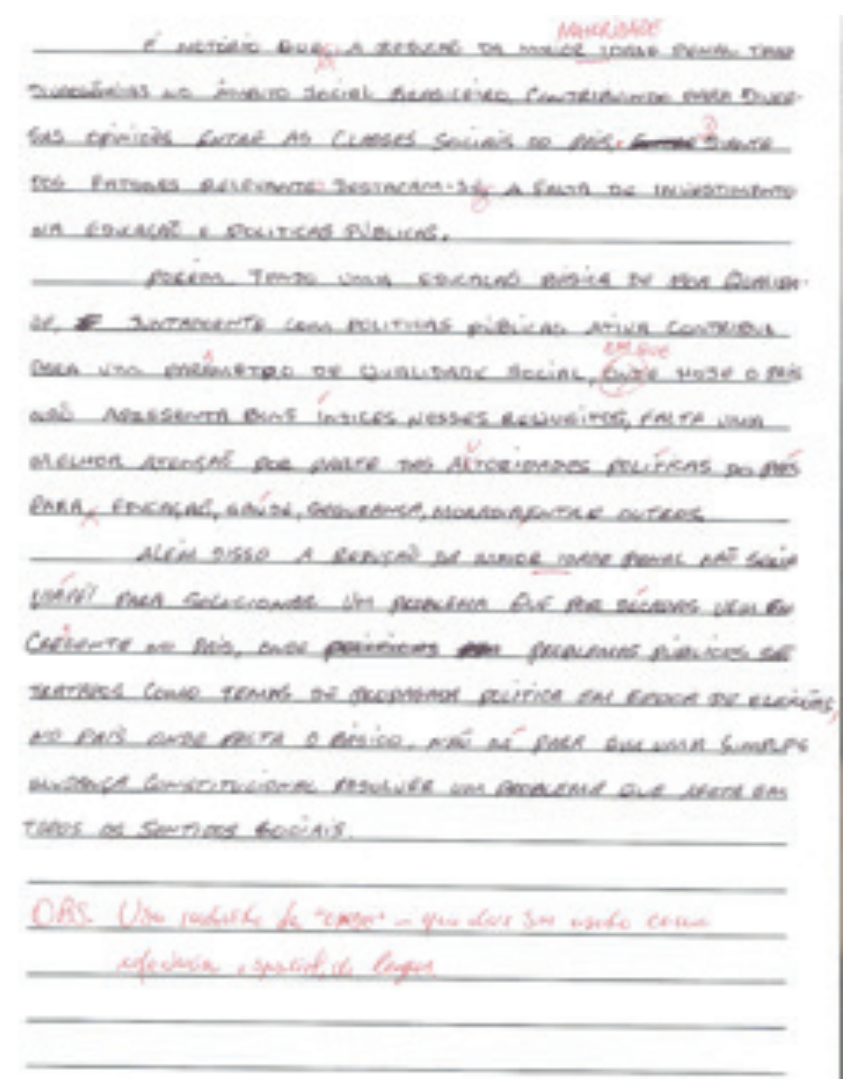

Figura 3: Texto com menos problemas de textualidade no grupo de estudantes da oficina

Fonte: Arquivo pessoal dos autores. Texto elaborado por estudante da oficina em foco.

A avaliação foi feita em cada texto e devolvida aos estudantes para que pudessem refletir e reescrever os seus textos em um segundo encontro que, como comentamos, não foi possível. Isso e a impossibilidade de fazer um trabalho mais longo com os estudantes são os dois aspectos que foram avaliados negativamente no desenvolvimento do projeto. No entanto, um olhar sobre essas produções textuais permite compreender não só a heterogeneidade da turma de EJA, mas a possibilidade de interferir positivamente em sua formação, gerando um processo reflexivo acerca de sua própria produção e indicando as necessidades de adequação de seu texto à escrita mais formal, exigida em concursos e seleções públicas, algo que atinge diretamente seus interesses de crescimento pessoal e profissional. 


\section{CONSIDERAÇÕES FINAIS}

A necessidade de "associação teoria-prática" proposta pela LDB 9.394/96 para a formação no ensino superior é assumida pelo IFRN ao propor a extensão como uma das formas de pôr em prática os conteúdos trabalhados nas instituições formadoras. Em outras palavras, o pensar reflexivo necessita de um aporte teórico para estabelecer as possibilidades de reflexão. Nessa linha de pensamento, a experiência aqui relatada centra esforços no sentido de proporcionar aos estudantes em formação no ensino superior um contato com a realidade educacional de seu município, de forma mais participativa.

Trabalhar a língua portuguesa não é apenas reproduzir conhecimentos já cristalizados, é discutir cotidianamente o sujeito e seu estar no mundo, seja esse sujeito o professor, voltado para uma reflexão sobre sua prática, seja o aluno, que precisa estar inserido em um processo que o faça desenvolver seu espírito crítico. É o pensar a prática e os sujeitos envolvidos nessa prática que visa todo o processo aqui apresentado.

A partir desse pensar, cumpre elaborar atividades que possam, de fato, atender à demanda dos alunos e alunas da modalidade EJA. Atividades que partam, por exemplo, da reflexão sobre temas do cotidiano, de interesses pessoais, de necessidades profissionais. A articulação entre a compreensão sobre o texto (leitura) e a posterior produção escrita pode instigar interpretações mais críticas e a compreensão de suas necessidades de desenvolvimento.

Mas, para além desses aspectos, espera-se, conhecendo essa modalidade e esses indivíduos, prover um ambiente de reflexão sobre o ensino de Língua Portuguesa no nível médio para a modalidade EJA e prover elementos para a compreensão dos problemas ligados à recepção e manutenção desses alunos na escola a partir de uma prática que os levem a refletir sobre sua identidade e seus projetos de futuro.

Os textos produzidos proporcionam um melhor conhecimento daquele público específico e sua avaliação indica uma heterogeneidade intrínseca à realidade das turmas de EJA e, por isso, a necessidade de atendê-los de forma mais individualizada quanto à leitura e a escrita.

Novos projetos têm sido desenvolvidos em outras escolas e também para turmas de EJA de Ensino Médio. As experiências com essa turma, no entanto, levaram a novas propostas de oficinas e a novos olhares sobre esse público.

\section{REFERÊNCIAS}

AZEVEDO, I. B. O prazer da produção científica: diretrizes para a elaboração de trabalhos científicos. 10. ed. São Paulo: Hagnos, 2004.

ARROYO, Miguel Gonzáles. Educação de Jovens-Adultos: Um campo de direitos e de responsabilidades públicas. In: SOARES, Leôncio et al. Diálogos da educação de jovens e 
adultos. Belo Horizonte: Autêntica. 2005.

BARREYRO, Gladys Beatriz. "Programa Alfabetização Solidária": terceirização no contexto da Reforma do Estado. In: Educar em Revista, Curitiba: Editora UFPR, n. 38, set./dez. 2010, p. 175-191.

BECHARA, Evanildo. Gramática escolar da língua portuguesa. Rio de Janeiro: Lucerna, 2001.

BRASIL. Parâmetros curriculares Nacionais para o ensino médio. Brasília: MEC/SEMTEC, 1999.

.Decreto 5.154/2004. In. Educação profissional e tecnológica: legislação básica. 6. ed. Brasília: SETEC, 2005.

Relatório Educação para todos no Brasil: 2000-2015 [versão preliminar]. MEC: Brasília, Junho, 2014. Disponível em http://portal.mec.gov.br/index.php?option=com _ docman\&view=download\&alias=15774-ept-relatorio-06062014\&ltemid=30192 Acesso em 30 de maio de 2015.

Plano Nacional de Educação. Lei No 13.005, de 25 de Junho de 2014. Disponível em http://www.planalto.gov.br/CCIVIL_03/_Ato2011-2014/2014/Lei/L13005.htm. Acesso 31 de maio de 2016.

Política Nacional de Extensão Universitária. Disponível em: http://www.renex.org.br/ documentos/2012-07-13-Politica-Nacional-de-Extensao.pdf. Acesso em: 09 mar. 2016.

Diretrizes Curriculares Nacionais Gerais da Educação Básica. Brasília: MEC/ SEB/DICEI, 2013. Disponível em http://portal.mec.gov.br/index.php?option=com_ docman\&view =download\&alias $=13448$-diretrizes-curiculares-nacionais-2013pdf\&ltemid=30192. Acesso em 01 de novembro de 2017.

BRASIL/MEC/SETEC. Decreto 5.154/2004. In. Educação profissional e tecnológica: legislação básica. 6. ed. Brasília: SETEC, 2005.

BRASIL/MEC/SETEC. Trabalhando com a educação de jovens e adultos: alunas e alunos da EJA. Brasília: SETEC, 2006.

CERQUEIRA, Teresa Cristina Siqueira. O professor em sala de aula: reflexão sobre os estilos de aprendizagem e a escuta sensível. In: Psic. [online]. jun. 2006, vol.7, no.1, p.29-38. Disponível em: http://pepsic.bvspsi.org.br/scielo.php?script=sci_ arttext\&pid=S167673142006000100005\&lng=pt\&nrm=iso ISSN 1676-7314. Acesso: 08 de setembro, 2007.

CIAVATTA, Maria. A formação integrada: escola e o trabalho como lugares de memória e de identidade. In: FRIGOTTO, Gaudêncio; CIAVATTA, Maria; RAMOS, Marise. (Orgs.). Ensino médio integrado: concepções e contradições. São Paulo: Cortez, 2005. 
D’AMBRÓSIO, U. Educação para uma sociedade em transição. Campinas: Papirus, 1999.

DAMIANI, Magda Floriana. Entendendo o trabalho colaborativo em educação e revelando seus benefícios. Revista Educar: Curitiba: Editora da UFTPR, n.31, p. 213-230, 2008, p. 12-13.

DEMO, Pedro. Educar pela pesquisa. Campinas: Editora Autores Associados, 2000.

DIONÍSIO, Ângela Paiva; MACHADO, Anna Rachel; BEZERRA, Maria Auxiliadora (org.). Gêneros textuais e ensino. 3. ed. Rio de Janeiro, Lucerna, 2005.

FREIRE, Paulo. Pedagogia do oprimido. São Paulo: Paz e Terra, 1970, 23ª Edição, 1996.

Extensão ou comunicação? 12 ed. Rio de Janeiro: Paz e Terra, 2002.

GIROUX. Henry. Teoria crítica e resistência em educação. Tradução de Ângela Maria B. Biaggio. Petrópolis: Vozes, 1986.

IBAIXE, Carmensita de Souza Bueno; SOLANOWSKI, Marly; IBAIXE JR., João. Preparando aulas: manual prático para professores, passos para a formação do educador. São Paulo: Madras, 2006.

IFRN. RESOLUÇÃO Nº. 35, de 22 de novembro de 2006. Disponível em: http://portal.ifrn.edu.br/ extensao/resolucoes/resolucao-no-35-de-22-de-novembro-de-2006/view. Acesso em: 09 mar. 2016.

Projeto Político Pedagógico. Disponível em: http://portal.ifrn.edu.br/institucional/ projeto-politico-pedagogico. Acesso em: 29 de março de 2016.

LUCENA, Ivone Tavares de. Fiando as tramas do texto. João Pessoa: Edições CCHLA, 2004.

MELLO, Guiomar Namo. Cidadania e competitividade. 9 ed. São Paulo: Cortez, 2002. MORIN. E. A cabeça bem feita: repensar a reforma, reformar o pensamento. Rio de Janeiro: Bertrand Brasil, 2000.

NOVA Escola online. Edição 167. Novembro de 2003. Disponível em: http://antigo.revistaescola. abril.com.br/edicoes/0167/aberto/mt_247721.shtml Acesso: 23 de agosto de 2008. 